\title{
The State of Faculty Involvement in Governance in the United States
}

\author{
Michael T. Miller \\ Higher Education Program, University of Arkansas \\ 153 Graduate Education Building, Fayetteville, AR 72701 \\ Tel: 1-479-575-3582Ｅ-mail: mtmille@uark.edu
}

Received: April 1, $2020 \quad$ Accepted: May 20, $2020 \quad$ Published: May 26, 2020

doi: 10.5296/ire.v8i2.17096 URL: https://doi.org/10.5296/ire.v8i2.17096

\begin{abstract}
The purpose of the study was to profile the state of faculty governance in US higher education. The survey was based the National Data Base on Faculty Involvement in Governance. Using a similar protocol, the study used survey research with a sample of research university faculty senate presidents. Results include a growing use of non-tenure track faculty and faculty with little senate experience being elected to lead senates. The presidents indicated that the skills most necessary to them are problem analysis, judgement, sensitivity, and oral/written communication skills. They perceived their primary task as developing a sense of direction for the senate, and the most critical issue they face is one of determining institutional priorities. The study was limited to only one type of institution (research-centered) in one country (the United States), and with a 38\% response rate to the survey. A growing number of non-tenure track faculty have been identified as leading senates and that there is a group of 'fast-track' senators with limited experience being elected into leadership positions. This means that there may be significant changes in how shared governance is being socially constructed. The study re-establishes the annual survey of faculty senate leaders, and longitudinal data will be critical in determining the future of faculty senates. Findings have immediacy in helping senate presidents and administrators understand the changing role of senates, how they see themselves, and what they value.
\end{abstract}

Keywords: Decision-making, Faculty Governance, Faculty Service 


\section{Introduction}

The American perspective on higher education includes a strong, historical inclusion of shared governance (Rosser, 2003). The modernization of higher education has minimized the role of faculty in governance in many ways, relying instead on the fiscal and efficient elements of institutional management (Schoorman, 2018). Despite the increasingly business-oriented university, faculty still maintain a pronounced role in institutional decision-making, motivated by either history, a defense of the curriculum, fears of compromised academic freedom, accreditation standards, or even the historic AAUP Statement on Academic Governance.

Trends in higher education management, whether directed by boards of trustees, leader motivation, financial distress, student demand or some other prompt continue to place the administrative and managerial function of the academy at the forefront of decision-making. The result of this movement is a continued refocusing on what faculty governance units engage in and the content of the agendas that they implement each year. Research has shown that much of the faculty agenda is unique to a specific institution's governing body, and typically does not intersect with other agendas on campus (Miller \& Nadler, 2018).

Faculty governance units are typically referred to as a 'faculty senate' or at some institutions, an 'academic senate.' The nomenclature varies as does the organizational structure, as some state-level university systems have a defined system-wide senate, with individual 'chapters' on campuses. Other models have discrete, stand-alone faculty senates on each campus. And, despite the emphasis on shared governance by faculty members, there has been little consistent evidence that their involvement makes an impact on institutional decision-making.

Between 1994 and 1999, the University of Alabama hosted the National Data Base on Faculty Involvement in Governance (NDBFIG), a data set developed from a number of individual institutional surveys of shared governance practices on those campuses. A goal of the NDBFIG was to begin to understand, nationally, what was happening with shared governance units, primarily faculty senates, and to look for commonalities across institutions. The current study extends this work from two decades ago by re-establishing a national annual study of faculty senate leaders and their perceptions of important and critical issues on their campuses.

\section{Background of the Study}

There have been multiple perspectives on the appropriate role for faculty involvement in governance in recent years. The corporate perspective of institutional operations, a perspective that stresses financial gain and stability, has grown and has come to stress efficiency and profit over process (Ilyas, 2017). This means that the historically-rooted shared decision-making that has been an integral part of the academy has, to some extent, become threatened (Vican, Friedman, \& Andreasen, 2020). This perspective has been particularly noted in such areas as how institutional leadership searches are conducted. Once an open process that stressed stakeholder input, many of these searches are now conducted in private with only a final candidate being presented to the institution (Dettmar \& Glick, 2019).

The illustration of how leadership searches are conducted is reflective to some extent on the 
value placed in shared decision-making by governing boards. Legally, these governing boards have the responsibility and duty to their constituents (typically the public and the state) for the operation and quality of the institution (Davies, 2011), yet through their appointment processes, few have any sort of formal accountability measure built into their terms that would indicate or reflect that the individual's efforts are truly focused on the preservation of the institution. To some extent, boards now have the authority to do whatever they please (Ellis, 2020).

The argument provided by many holding the political view of limited or reduced shared governance is that the premise of higher education has changed. No longer are universities driven primarily by their contribution to the public good and the benefits an educated population bring to their communities. Instead, university's, they claim, have become focused on individualism and individual benefit (aka, higher salary) that comes from a higher education experience (Hersh \& Merrow, 2006). This thinking stresses professional programming with jobs as an outcome of the college experience, and, largely an opinion that institutions must stress efficiency in operations, including in how education is delivered (Miller \& Nadler, 2020).

The alternative discussion of shared governance focuses on how curriculum and the student experience is best arranged, and that critical thinking, communication, and involvement skills are all paramount to a college experience. This thinking stresses the development of the student rather than the outcome of job training as the goal of higher education (Gregory, 2003; Miller \& Nadler, 2020). This argument becomes centered in the use of shared governance, as the process of debating and considering multiple perspectives transcends the efficiency of the student experience.

In addition to these philosophical governance considerations, there are practical administrative barriers and opportunities that influence the use and reliance of shared governance. Administrators increasingly view the financial realities of higher education as placing entire institutions at risk, and this fiscal concern shifts accountability from the content of the college experience to the ability of an institution to pay its obligations. This concern over funding includes tuition and rising fees, how much faculty members are paid, and increasingly, the privatization of services for institutional profit (Kezar, Maxey, \& Holcombe, 2016). Once the concern of the institution becomes fiscal rather than academic, the desire to give attention to shared governance diminishes.

Faculty members, however, do not always help themselves with the responsibility of sharing authority on their campuses. Slow decision-making, in-fighting among faculty members, an inability or unwillingness to canvas public opinion, and irrational demands can all frame a faculty senate as problem rather than a partner in finding solutions (Lougheed \& Pidgeon, 2016; Miller, Williams, \& Garavalia, 2003).

And finally, the growing professionalization of the entire academy can work against sharing authority. Professional administrators, for example, might care more for their own advancement and career trajectory rather than their institution, and this same thinking can be found with a growing number of faculty (Gerber, 2014). The professoriate is increasingly mobile, chasing prestigious institutions and higher salaries rather than committing to spending a career at a single institution. These high-profile faculty members are also the 
individuals who are poised to be stolen by other institutions with higher salaries and better resources (Caesar, 2000).

The culmination of all of these factors is a confusing time for shared governance in higher education. Although regional accrediting bodies continue to require 'broad-based, inclusive decision-making,' that stipulation becomes increasingly difficult to measure, justify, and understand. In many cases this has become an area for academic matters only, such as curriculum, and the broad span of shared governance of the mid-20 $0^{\text {th }}$ century can be seen restricting quickly in the face of current fiscal realities. This backdrop, one of opportunity and threat, frames the current study to understand what is happening with faculty governance units, what they are addressing, and ultimately, attempting to understand where opportunities for a stronger alliance might reside.

\section{Research Procedures}

The sample for data collection was purposefully developed by selecting all public Carnegie classified Very High Research and High Research Activity universities. The total number of institutions identified was 185 (94 public Very High Research Activity and 91 High Research Activity), and each institution was manually searched on the internet to identify the current faculty senate leader at each institution. Three institutions were removed from the listing for different reasons, including one was an international institution in a US territory, one was an upper-level service academy without a shared faculty governance unit, and one had a self-identified non-active faculty senate at this time. Therefore, the total number of faculty governance leaders included in the study was 182 .

In several state higher education systems, there was a system-wide governance unit, sometimes called a 'University Senate.' These models of faculty participation in governance typically included a stand-alone governance body (faculty council or faculty senate) on the individual campuses, and they also participate in this larger system-wide governance group. In these situations, the campus governance leader from the Carnegie classified institution was selected for inclusion in the study on the basis of the individual holding the primary campus leadership position, representing the voice of the faculty on that particular campus.

Data were collected using a researcher-developed on-line survey instrument. The instrument contained five distinct sections: (1) general respondent information, (2) agreement related to specific leadership skills, (3) agreement of specific tasks related to running a faculty senate, (4) strategies for improving shared governance, and (5) the identification of critical issues facing faculty governance. The skills and tasks were drawn from educational management related literature, and the strategies and critical issues were identified in the current literature and popular news related to shared governance. A draft of the survey instrument was provided to a panel of faculty senate leaders at non-research universities. Following several revisions, a pilot test of the instrument was conducted with comprehensive university faculty governance leaders resulting in a Cronbach alpha of .6322 .

\section{Findings}

Based on the data identified online in searching for the sample participants, including all 182 faculty senate presidents, just over half of all individuals holding the faculty leadership 
position held the academic rank of professor $(n=94 ; 51.6 \%)$ and over a third held the rank of associate professor $(n=67 ; 36.8 \%$; see Table 1$)$. Additionally, 16 institutions had faculty governance leaders with non-career ladder titles, including instructors, lecturers, courtesy faculty, or modified titles, such as teaching faculty or research assistant professor.

Table 1. Faculty Leaders Rank and Disciplinary Distribution, N=182

\begin{tabular}{lll}
\hline & $n$ & $\%$ \\
\hline Professor & 94 & $51.6 \%$ \\
Associate Professor & 67 & 36.8 \\
Assistant Professor & 5 & 2.7 \\
Modified Title & 16 & 8.7 \\
\hline
\end{tabular}

The faculty leader's held a variety of titles for leading the governance body, with just over half of using the title chair $(n=92 ; 50.5 \%)$, nearly as many used the title president $(n=81$; $44.5 \%)$, and several senates $(n=9 ; 4.9 \%)$ used titles unique to their institution, such as Secretary of the Senate, Presiding Faculty Member, and Speaker of the Senate.

Those holding the senate leadership positions were closely divided between men ( $\mathrm{n}=99 ; 54 \%)$ and women $(\mathrm{n}=83 ; 45 \%)$. As shown in Table 2 , the most popular academic disciplines represented by these faculty governance leaders were the Liberal Arts $(n=57 ; 31 \%)$, Engineering $(n=30 ; 16 \%)$, and the Social Sciences $(n=26 ; 14 \%)$.

Table 2. Academic Disciplinary Homes of Faculty Governance Leaders

\begin{tabular}{lll}
\hline & $n$ & $\%$ \\
\hline Liberal Arts & 57 & $31.3 \%$ \\
Engineering & 30 & 16.4 \\
Social Sciences & 26 & 14.2 \\
Health/Medicine & 24 & 13.1 \\
Business & 16 & 8.7 \\
Law & 9 & 4.9 \\
Agriculture & 8 & 4.3 \\
Education & 8 & 4.3 \\
Library & 4 & 2.1 \\
\hline
\end{tabular}

The survey was distributed to 182 faculty governance leaders in January 2020. Data collection ceased after three follow up email messages in February 2020 with 70 usable, 
completed survey responses. Four responses were begun but were not completed, meaning that the usable survey response rate was $38.46 \%$. As a note, there were numerous emailed responses to the survey indicating a refusal to participate. Many of these responses were based on a distrust of what responses might be used for, what the findings might indicate to administrators, and for at least three sample members, an indication that senates do not have 'leaders,' but rather, 'facilitators' who guide the senate rather than control it.

Senate leaders who completed the survey were asked to identify both their tenure status and their length of service in the faculty senate. The majority of senate leaders were tenured $(\mathrm{n}=59 ; 84.2 \%)$, although over $10 \%$ of the respondents indicated that they did not serve in a tenure-stream faculty position $(n=8 ; 11.4 \%)$. The distribution of length of service was even across service categories, with the majority of senate presidents having served less than five years $(n=26 ; 37.1 \%)$, more than 10 years $(n=24 ; 34.2 \%)$, or having served between $5-10$ years $(n=20 ; 28.5 \%$; see Table 3$)$.

Table 3. Characteristics of Faculty Governance Leaders, $\mathrm{N}=70$

\begin{tabular}{lll}
\hline Characteristic & $n$ & $\%$ \\
\hline Tenure status & 59 & $84.2 \%$ \\
$\quad$ Tenured & 3 & 4.2 \\
Tenure track, non-tenured & 11.4 \\
Non-tenure track & 8 & \\
& & \\
Length of Service & 24 & 34.2 \\
More than 10 years & 20 & 28.5 \\
5-10 years & 26 & 37.1 \\
Less than 5 years & & \\
Role & 70 & 100.0 \\
President/leader & & \\
\hline
\end{tabular}

Senate leaders were also asked if they agreed or disagreed with certain skills being necessary for faculty governance leadership. There was complete agreement that problem analysis, judgment, oral and written communication skills, and sensitivity were necessary (all $n=70$; $100 \%$ ). The greatest disparity of agreement was for the skill of 'range of interests' (ability to discuss a variety of issues) which had over a quarter of respondents disagree with its importance $(\mathrm{n}=18 ; 25.72 \%)$. 
Table 4. Skills Necessary for Faculty Governance Leadership, N=70

\begin{tabular}{lllll}
\hline & $n$ Agree & $\%$ Agree & $n$ Disagree & $\%$ Disagree \\
\hline Problem analysis & 70 & $100.00 \%$ & 0 & $0.00 \%$ \\
Judgement & 70 & 100.00 & 0 & 0.00 \\
Oral communication skills & 70 & 100.00 & 0 & 0.00 \\
Written communication skills & 70 & 100.00 & 0 & 0.00 \\
Sensitivity & 70 & 100.00 & 0 & 0.00 \\
Leadership & 68 & 97.14 & 2 & 2.86 \\
Educational values & 68 & 97.14 & 2 & 2.86 \\
Organizational ability & 66 & 94.28 & 4 & 5.72 \\
Decisiveness & 66 & 94.28 & 4 & 5.72 \\
Stress tolerance & 62 & 88.57 & 8 & 11.43 \\
Range of interests & 52 & 74.28 & 18 & 25.72 \\
\hline
\end{tabular}

Academic leaders and administrators are often asked to take on a variety of tasks, and six different tasks that pertained to faculty senate leaders were included in the survey. Responding faculty leaders were asked to rate their level of agreement with each item on a 1-to-5 Likert-type scale, where 1=Strongly Agree progressing through 5=Strongly Disagree. Respondents agreed most strongly that they undertake the tasks of developing a sense of direction for the senate $(\bar{x}=1.91)$, take care of details for running senate meeting $(\overline{\mathrm{x}}=2.89)$, and develop linkages and networks to assist in leading the senate $(\bar{x}=3.26)$. They agreed least that their task was to obtain and allocate resources to run the senate $(\bar{x}=4.54)$ and developing data bases to use in decision-making for the senate $(\bar{x}=4.89$; see Table 5). These task ratings were then separated by length of service on the faculty senate based on the assumption that time serving in the senate might produce a different perspective on what the role requires. As shown in Table 6, the resulting order of the mean ratings was the same for those leaders who had served more than 10 years or 5-10 years; however, those who had served less than 5 years agreed more with the importance of developing networks than the details of running the senate or developing a sense of pride.

Table 5. Tasks Associated with Leading Faculty Governance

\begin{tabular}{lccc}
\hline & Mean & SD & Variance \\
\hline Develop sense of direction & 1.91 & .87 & .76 \\
Take care of details for running & 2.89 & 1.65 & 2.73 \\
Develop networks and linkages for yourself as leader & 3.26 & 1.61 & 2.59 \\
Develop sense of pride & 3.51 & 1.59 & 2.54 \\
\hline
\end{tabular}


Obtain and allocate resources

An Analysis of Variance identified significant differences in the ratings, and a Tukey-post hoc test identified that there was a significant difference in the mean ratings for the 10 or more years of service and the 5-10 years of service faculty leaders than the under 5 years of service leaders on developing a sense of direction for the senate (see Table 6). The long-serving faculty leaders (10+ years) had a significantly higher level of agreement on the tasks of taking care of the details of running the senate and obtaining and allocating senate resources.

Table 6. Governance Tasks by Length of Senate Service

\begin{tabular}{lllll}
\hline & $10+$ & $5-10$ & $<5$ & All \\
\hline Develop sense of direction & $\mathbf{1 . 0 4}$ & $\mathbf{1 . 6 5}$ & 2.92 & $1.91^{*}$ \\
Take care of details for running & $\mathbf{1 . 7 5}$ & 2.85 & 3.96 & $2.89^{*}$ \\
Develop networks and linkages for yourself as leader & 3.45 & 3.20 & 3.11 & 3.26 \\
Develop sense of pride & 3.54 & 3.65 & 3.38 & 3.51 \\
Obtain and allocate resources & $\mathbf{4 . 0 8}$ & 4.76 & 4.80 & $4.54^{*}$ \\
Develop data bases for decision making & 4.95 & 4.89 & 4.90 & 4.89 \\
\hline
\end{tabular}

$* \mathrm{p}<.05$

Responding faculty senate leaders agreed unanimously (see Table 7) with four strategies for positively improving faculty shared governance, including convincing the administration of the value of the faculty voice, responsible actions by faculty when called on for service, encouraging administrators to consult with faculty on a consistent basis, and implementing procedures that involve faculty early in the decision-making process. Nearly $90 \%$ of the respondents agreed with all of the strategies identified, although the least agreed upon strategy was that of faculty committee chairs meeting regularly with the administration to discuss project progress ( $88 \%$ agreement).

Table 7. What Would Positively Improve Faculty Shared Governance

\begin{tabular}{lll}
\hline & \# Agree & \# Disagree \\
\hline $\begin{array}{l}\text { Convince administration that the faculty voice is valuable in decision } \\
\text { making }\end{array}$ & 70 & 0 \\
$\begin{array}{l}\text { Faculty must act responsibly when called on for service } \\
\text { Encourage administration to consult with faculty leader in a }\end{array}$ & 0 \\
$\begin{array}{l}\text { consistent and visible manner in the governance process } \\
\text { Implement institutional procedures which involve faculty governance }\end{array}$ & 0 \\
\hline
\end{tabular}


systems early in the decision-making process

Faculty leaders must encourage more potential leaders to become $68 \quad 2$ involved

Utilize the faculty senate as a conduit in which faculty participation 68 is solicited

Increase participation of faculty in long-, short-, and strategic 68 planning

Faculty must insist on their rights and responsibilities in appropriate 66 governance roles

Empower faculty to question long-range planning initiatives

66

4

Reward excellence in faculty participation via tenure, promotion, and 64 merit decisions

Faculty committee chairs should meet regularly with administration 62 to discuss project progress

The last section of the survey asked responding faculty leaders to identify their agreement with several critical issues now facing faculty governance. These items used a 1-to-3 Likert-type scale, where 1=Low Agreement, 2=Undecided, and 3=Strong Agreement, noting that this was a different scale than that used for the ratings of tasks. As a group, responding presidents identified institutional priorities $(\bar{x}=2.61$; see Table 8$)$, compensation and benefits $(\bar{x}=2.47)$ and inadequate institutional finance $(\bar{x}=2.47)$ as the most agreed upon critical issues that they face. The agreed least with the automation of campus and academic programs removing faculty from decision-making $(\bar{x}=1.89)$ and that administrators did no respect faculty governance $(\bar{x}=1.72$; see Table 8$)$. When stratified by length of faculty service (10+ years, 5-10 years, under 5 years), the groups agreed most strongly with separate issues. The longest serving presidents agreed most strongly with the compensation and benefits issues $(\bar{x}=2.67)$, the 5-10 year serving presidents agreed most strongly with the inadequacy of institutional finances $(\bar{x}=2.90)$, and the presidents with under 5 years of service agreed most strongly with institutional priorities $(\bar{x}=2.61)$.

Table 8. Critical Issues Facing Faculty Governance

\begin{tabular}{llll}
\hline & Mean & SD & Variance \\
\hline Institutional priorities & 2.61 & .59 & .35 \\
Compensation/benefits & 2.47 & .69 & .47 \\
Institutional finance is not adequate & 2.47 & .73 & .53 \\
Decision-making precedents & 2.42 & .72 & .52 \\
Inclusive climate of campus & 2.39 & .76 & .57 \\
State oversight & 2.22 & .79 & .62 \\
\hline
\end{tabular}


Free speech/academic freedom

Administrators do not understand faculty

Collaboration with student government

Automation removing faculty decision-making

Administrators do not respect faculty governance

1.72

.84 .70

Note: Three point scale with 1=Agree, $2=$ Undecided, and 3=Disagree .

Using a one-way ANOVA, three significant differences were identified (see Table 9), including the low rating of compensation and benefits by the senate presidents with the least experience, high mean rating of decision-making precedents and the inadequate institutional finance by the mid-level experienced presidents.

Table 9. Critical Issues by Length of Faculty Senate Service

\begin{tabular}{lllll}
\hline & $10+$ & $5-10$ & $<5$ & All \\
\hline Institutional priorities & 2.58 & 2.65 & 2.61 & 2.61 \\
Compensation/benefits & $\mathbf{2 . 6 7}$ & $\mathbf{2 . 8 5}$ & 2.00 & $2.47^{*}$ \\
Institutional finance is not adequate & 2.37 & $\mathbf{2 . 9 0}$ & 2.23 & $2.47^{*}$ \\
Decision-making precedents & 2.54 & $\mathbf{2 . 7 0}$ & 2.07 & $2.42^{*}$ \\
Inclusive climate of campus & 2.29 & 2.45 & 2.42 & 2.39 \\
State oversight & 2.25 & 2.30 & 2.11 & 2.22 \\
Free speech/academic freedom & 2.20 & 2.15 & 2.15 & 2.17 \\
Administrators do not understand faculty & 2.08 & 1.95 & 1.88 & 1.97 \\
Collaboration with student government & 1.95 & 1.80 & 1.96 & 1.92 \\
Automation removing faculty decision-making & 1.95 & 1.80 & 1.96 & 1.92 \\
Administrators do not respect faculty governance & 1.66 & 1.80 & 1.69 & 1.72 \\
\hline
\end{tabular}
$* \mathrm{p}<.05$.

\section{Conclusion and Discussion}

The response rate for the current study, nearly $40 \%$, was high for an online survey, and perhaps illustrates that there is an interest or need in continuing to explore the state of shared governance in higher education. Additionally, the strongly worded email messages from respondents suggests that there is a strong ideological perspective about shared governance by faculty that may well be distrustful or skeptical about examining the process. Regardless of the excitement or trust rationale for participating and voicing ideas about faculty governance, the interest level does indeed reflect the national conversation about trying to 
figure out what faculty shared governance is and can be in the $21^{\text {st }}$ century.

Findings in the study reflect some consistency and some variation in faculty senate leadership. Although senate leaders were mostly senior, tenured faculty, there was a very real presence identified of junior and non-tenure track faculty participation. This group of faculty leaders accounted for about $10 \%$ of all leaders with $15 \%$ of leaders not holding tenure, and may well be mirroring the changing reality of higher education that there might be fewer tenure-track faculty on university payrolls, that tenure-track faculty might have such a high research demand that they do not want to participate, or, that the value of providing service is higher in some types of faculty roles.

Over a third of those serving in faculty senate leadership roles had been involved less than 5 years, meaning that there is a critical mass of faculty senators who could be considered 'fast-trackers.' These individuals might have won their respective positions running as 'outsiders' or 'anti-establishment' candidates, or they could be the only individuals willing to take on the responsibility. The other perspective on this is that their motivations might be for self-proclamation, and as has been suggested in the literature, as a stepping stone to assuming an administrative position (Miller \& Pope, 2003).

In terms of skills and tasks, there was broadly strong agreement toward all of them identified in the survey. Respondents agreed with all of the skills necessary for faculty senate leadership, with complete agreement on five of the 11 identified skills. This high level of consensus illustrates the commonality of positions across institutions, and perhaps suggests that the positions may well have a great deal in common in their operational approaches to leadership. As for the tasks, the two with the highest level of agreement were developing a sense of direction and taking care of the details for running the senate. When explored in greater detail, however, presidents who had served on the senate for at least 10 years agreed significantly more on several tasks, perhaps suggesting some insight gained from experience.

There was collective strong agreement with the strategies for positively improving shared governance, including elements relating to working with administrators, but also in terms of individual faculty behavior. This could be a recognition to the highly deliberative process that senates have become known for, and in an age of attention toward efficiency, such slow deliberations may be seen by some as a detractor of the "good" of faculty governance.

Respondents agreed most with the critical issues facing faculty governance as institutional priorities, compensation and benefits, and the inadequacy of institutional finances. There were significant differences, however, identified for the compensation and benefits issues with the senate leaders with the least experienced leaders rating it lower than those with the most experience. This same differentiation in results was identified on the issue of institutional finance. These differences might be reflective of generational perspectives on the institution, but might also be reflective of older faculty taking a greater interest in personal issues, such as retirement benefits.

Overall, the current study begins to paint a portrait of those leading faculty senates in research universities, and suggests perhaps some changes in the landscape of shared governance. In particular, the rise in non-tenured or tenure-track faculty leading these organizations may well be an indication of the future of faculty governance. Similarly, the 
'fast-trackers' may be reflective of those faculty members looking for ways to begin working in administration. Subsequent administrations of surveys such as this may well help portray how faculty senates are operating, and hopefully, how they are making a difference in the welfare of higher education.

\section{References}

Davies, G. K. (2011). Perspectives: Changing roles of governing and coordinating boards. Change: The Magazine of Higher Learning, 43(4), 45-48. https://doi.org/10.1080/00091383. 2011.585299

Dettmar, K., \& Glick, S. (2019, July 2). Sorry, headhunters, but the healthiest presidential searches are open. Chronicle of Higher Education. Retrieved from https://www.chronicle. com/article/Sorry-Headhunters-but-the/246597

Caesar, T. (2000). Traveling through the boondocks in and out of the academic hierarchy. Albany, NY: SUNY Press.

Ellis, L. (2020, February 3). This university's board now has the power to fire anyone - even down to the janitor. Chronicle of Higher Education, retrieved online at https://www.chronicle.com/article/This-University-s-Board-Now/247957?utm_source=at\&ut m_medium $=$ en\&cid $=$ at\&source $=$ ams\&sourceId $=499896$

Gerber, L. G. (2014). The rise and decline of faculty governance: Professionalization and the modern American university. Baltimore, MD: Johns Hopkins University Press.

Gregory, M. (2003, September 12). A liberal education is not a luxury. Chronicle of Higher Education, B16, Retrieved from https://chronicle.com/article/A-Liberal-Education -Is-Not-a/ 4955

Hersh, R. H., \& Merrow, J. (2006). Declining by degrees, higher education at risk. New York, NY: St. Martin's Press Griffin.

Ilyas, M. (2017). Making of a corporate university model: Transition from traditional training to learning management system. Journal of Education and Practice, 8(15), 85-90.

Kezar, A., Maxey, D., \& Holcombe, E. (2016). The professoriate reconsidered: A study of new faculty models. Thought and Action, 32(1), 65-88.

Loughleed, P., \& Pidgeon, M. (2016). Exploring effective academic governance at a Canadian university. Canadian Journal of Higher Education, 46(3), 90-104.

Miller, M. T., \& Nadler, D. P. (2020). How colleges and universities create the value of their degrees: Beyond the formal curriculum. In W. Nunninger (ed.), Handbook of Research on Quality Assurance and Value Management (2 ${ }^{\text {nd }}$ ed., pp. 81-99). Hershey, PA: IGI Global. https://doi.org/10.4018/978-1-7998-1238-8

Miller, M. T., \& Pope, M. L. (2003). Faculty senate leadership as a presidential pathway: Clear passage or caught in a maze? Community College Journal of Research and Practice, 27(2), 119-130. https://doi.org/10.1080/713838116

Miller, M. T., Williams, C., \& Garavalia, B. J. (2003). Path analysis and power rating of communication channels in a faculty senate setting. In M. T. Miller, \& J. Caplow (Eds.), Policy and University Faculty Governance (pp. 59-74). Greenwich, CT: Information Age. 


\section{Macrothink}

International Research in Education

ISSN 2327-5499

2020, Vol. 8, No. 2

Nadler, D. P., \& Miller, M. T. (2018, October). Student and faculty senate agenda alignment: A test of comprehensive shared governance. Annual Meeting of the Midwest Educational Research Association, Cincinnati, $\mathrm{OH}$.

Rosser, V. J. (2003). Historical overview of faculty governance in higher education. In M. T. Miller and J. Caplow (eds.), Policy and University Faculty Governance (pp. 3-18). Greenwich, CT: Information Age Publishing.

Schoorman, D. (2018). The erosion of faculty governance. In J. L. DeVitis, \& P. A. Sasso (eds.), Colleges at the crossroads, taking sides on contested issues (pp. 237-254). New York, NY: Peter Lang Publishing.

Vican, S., Friedman, A., \& Andreasen, R. (2020). Metrics, money, and managerialism: Faculty experiences in competing logics in higher education. Journal of Higher Education, 91(1), 139-164. https://doi.org/10.1080/00221546.2019.1615332

\section{Copyright Disclaimer}

Copyright reserved by the authors.

This article is an open-access article distributed under the terms and conditions of the Creative Commons Attribution license (http://creativecommons.org/licenses/by/4.0/). 